\title{
Effects of dietary fructo-oligosaccharides on laying performance and serum biochemical parameters of yellow broiler breeder hens
}

\author{
Zhao Feng ${ }^{2}$, Xia Zhongsheng ${ }^{1}$ \\ ${ }^{1}$ College of Animal Science and Technology, University, Nanning 530005, China; \\ ${ }^{2}$ Hainan Radio \& TV University, Haikou 570208, China
}

\begin{abstract}
:24-week-old local yellow broiler breeder hens were selected to study the effects of dietary fructo-oligosaccharides(FOS)or antibiotics(bacitracin zinc)on laying performance, serum biochemical indices and dietary mutrient metabolizability. The results showed that: compared with the control group, dietary FOS supplemented with $0.2 \%, 0.4 \%, 0.6 \%$ could increase the laying rate,average egg weight, feed egg ratio, eggs percent of pass, fertility rate and hatchability of qualified egg, and reduce serum levels of total cholesterol and triglyceride, and improve the apparent metabolizability of dietary nutrients. The effects of diet supplemented with FOS was better than those of diet supplement with $0.05 \%$ antibiotics.It was suggested that the appropriate additive amount of FOS in diets for yellow broiler breeder hens should be $0.4 \%$
\end{abstract}

\section{Introduction}

With the development of social economy and the improvement of people's living standards, consumers are extremely concerned about the food safety of animal products and their impact on human health. Many shortcomings such as drug residues and bacterial resistance caused by long-term use of feed antibiotics have been highly valued by relevant institutions, research scholars and animal producers. Countries such as Europe and Japan have banned the use of antibiotics in feed. China's use of feed antibiotics has also severely restricted its types, dosages and methods. Therefore, the search for new green feed additives has become one of the hot spots of animal nutrition and feed science. The aim of this study is to investigate the effects of different levels of FOS in the diet on egg laying performance, serum biochemical indicators and metabolizability of high-quality yellow broiler hens. Besides, the goal is to compare them with antibiotics, to explore the appropriate level of FOS in the diet and the feasibility of replacing the antibiotics so as to provide reference for the rational use of FOS in the production of yellow broilers hens.

\section{Materials and Methods}

\subsection{Animal Test and Experiment Design}

The test FOS preparation (powder, containing 30\% fructose) and the bacitracin zinc preparation (containing $15 \%$ bacitracin zinc) are commercially available products. The experiment is carried out in a chicken farm. 810 chickens are randomly divided into 1 control group and 4 experimental groups, with 5 treatment groups, 162 chickens in each group, and 3 replicate groups, 54 in each group ( 3 chickens are placed in 1 cage). The control group is fed a basal diet, and the four experimental groups are fed a test diet supplemented with $0.2 \%$ FOS, $0.4 \%$ FOS, $0.6 \%$ FOS and $0.05 \%$ bacitracin zinc formulation on a basal diet basis.

\subsection{Feeding Management}

The test house is a water curtain type house with windows. It adopts a three-tiered cage type, with 3 kinds of chicken per cage, forced ventilation of the exhaust fan, free drinking and feeding, minimizing the times of immunizations in order to prevent the stress response and ensure the stability of the test flock. Adaptation feeding is carried out for 7 days before the start of the formal test, and the formal test was conducted for 7 weeks until there are no significant differences in the physiological and production indexes of each group. Other management proceeds in accordance with the normal procedures of the chicken farm.

\subsection{Observation Indicators and Methods of Measurement}

\subsubsection{Production Performance Indicators}

The amount of eggs laid, the number of qualified eggs, the average egg weight, the feed intake, etc. are recorded on a daily basis. The eggs of each group are weighed 
weekly to check the weight changes of each group, and at the same time, the feather color and mental condition of chicken are observed. After collecting and numbering hatching eggs of each group, they are ready for incubation. The eggs are photographed after 7 days and the fertilization rate of each group is recorded to track the hatching rate of each group.

\subsubsection{Serum Biochemical Indicators}

On the morning of the experiment ended, 5 chickens are randomly selected from each group and are taken $5 \mathrm{ml}$ of blood sample on an empty stomach from their wing roots. The blood is placed in a $10 \mathrm{ml}$ sterile centrifuge tube at 45 degrees on a slope for two hours, and then is centrifuged to extract serum so as to determine serum biochemical indicators.

\subsubsection{Dietary Nutrient Metabolic Rate}

The nutrient metabolism rate of the diet is calculated according to the following formula:

Apparent digestibility $=[1-(\mathrm{b} / \mathrm{a}) \times(\mathrm{c} / \mathrm{d})] \times 100 \%$

In the formula, $a$ is the mass fraction $(\%)$ of a nutrient in the feed; $b$ is the mass fraction (\%) of a nutrient in the fecal sample; $\mathrm{c}$ is the mass fraction (\%) of the AIA in the feed; and d is the AIA of the fecal sample. Quality score $(\%)$.

\section{Results and Analysis}

\subsection{Production performance}

\subsubsection{Egg Production Rate and Egg Hatching Rate}

It can be seen from Table 1 that compared with the control group, the addition of FOS and bacitracin zinc in the diet can significantly increase the egg production rate of the yellow broiler hens $(\mathrm{P}<0.05)$. Compared with the control group, the egg production rate in the $0.2 \%, 0.4 \%$ and $0.6 \%$ FOS has respectively increased by $4.39 \%, 6.16 \%$ and $5.09 \%(\mathrm{P}<0.05)$, but the differences are not significant compared with the bacitracin zinc group $(\mathrm{P}>0.05)$. Compared with the control group, the qualified rate in the FOS group with $0.2 \%, 0.4 \%$ and $0.6 \%$ has respectively increased by $3.01 \%, 3.15 \%$ and $2.76 \%$ $(\mathrm{P}<0.05)$, which is slightly higher than that of bacitracin zinc group.

Table 1 Effect of Adding FOS and Bacitracin Zinc on Laying Performance of yellow broiler hens

\begin{tabular}{|c|c|c|c|c|c|}
\hline Group & Basic diet & $\begin{array}{c}0.2 \% \text { FOS } \\
\text { group }\end{array}$ & $\begin{array}{c}0.4 \% \text { FOS } \\
\text { group }\end{array}$ & $\begin{array}{c}0.6 \% \text { FOS } \\
\text { group }\end{array}$ & $0.05 \%$ antibiotics \\
\hline laying rate $\%$ & $70.18 \pm 0.81^{\mathrm{b}}$ & $73.26 \pm 1.66^{\mathrm{a}}$ & $74.50 \pm 1.29^{\mathrm{a}}$ & $73.75 \pm 0.44^{\mathrm{a}}$ & $72.81 \pm 1.15^{\mathrm{a}}$ \\
\hline $\begin{array}{c}\text { Egg Breeding Qualifi } \\
\text {-cation Rate } \%\end{array}$ & $92.70 \pm 0.45^{\mathrm{c}}$ & $95.49 \pm 0.44^{\mathrm{a}}$ & $95.62 \pm 0.17^{\mathrm{a}}$ & $95.26 \pm 0.35^{\mathrm{ab}}$ & $94.96 \pm 0.44^{\mathrm{b}}$ \\
\hline Ratio of feed to egg & $3.04 \pm 0.15 \mathrm{a}$ & $2.88 \pm 0.11 \mathrm{~b}$ & $2.77 \pm 0.04 \mathrm{c}$ & $2.78 \pm 0.13 \mathrm{bc}$ & $2.91 \pm 0.08 \mathrm{~b}$ \\
\hline Average egg weight /g·One ${ }^{-1}$ & $38.96 \pm 0.72^{\mathrm{c}}$ & $39.09 \pm 0.53 \mathrm{~b}^{\mathrm{c}}$ & $40.15 \pm 0.39^{\mathrm{a}}$ & $40.40 \pm 0.47^{\mathrm{a}}$ & $39.17 \pm 0.92^{\mathrm{b}}$ \\
\hline Fertity of setting eggs $/ \%$ & $94.32 \pm 0.55^{\mathrm{b}}$ & $95.14 \pm 1.43^{\mathrm{ab}}$ & $96.28 \pm 0.27^{\mathrm{a}}$ & $96.25 \pm 1.22^{\mathrm{a}}$ & $96.14 \pm 0.02^{\mathrm{ab}}$ \\
\hline Fertity of setting eggs $/ \%$ & $84.39 \pm 0.65^{\mathrm{c}}$ & $84.92 \pm 0.91^{\mathrm{c}}$ & $86.12 \pm 0.67^{\mathrm{ab}}$ & $86.33 \pm 1.38^{\mathrm{a}}$ & $85.52 \pm 0.75^{\mathrm{ab}}$ \\
\hline Number of dead takers/one & 6 & 3 & 4 & 3 & 3 \\
\hline
\end{tabular}

Note: The difference in the shoulder data of the peer data indicates that the difference is significant $(\mathrm{P}<0.05)$, and the difference indicates that the difference is not significant $(\mathrm{P}>0.05)$; the same below.

\subsubsection{Ratio of Feed to Egg}

As can be seen from Table 1, the addition of FOS and bacitracin zinc significantly reduces the feed-egg ratio compared with the control group $(\mathrm{P}<0.05)$. Compared with the control group, the feed-egg ratio of the $0.2 \%$, $0.4 \%, 0.6 \%$ FOS groups is respectively reduced by $5.26 \%, 8.88 \%$, and $8.55 \%$. The $0.2 \%$ and $0.6 \%$ FOS groups also decrease, compared with the bacitracin zinc group, but the difference is not significant $(\mathrm{P}>0.05)$.

\subsubsection{Average Egg Weight}

As can be seen from Table 1, the average egg weight of the yellow broiler hens in the $0.4 \%$ and $0.6 \%$ FOS groups respectively increases by $3.05 \%$ and $3.70 \%$, compared with the control group, which also increases by $2.50 \%$ and $3.14 \%(\mathrm{P}<0.05)$, compared with the bacitracin zinc group. The $0.2 \%$ FOS group also increases, compared with the control group, but the difference is not significant $(\mathrm{P}>0.05)$.

\subsubsection{Fertilized Rate and Hatching Rate of Qualified Eggs}

It can be seen from Table 1 that the addition of FOS and bacitracin zinc can improve the fertilization rate and hatching rate of the qualified eggs. The fertilization rate of qualified eggs of yellow broiler hens in the $0.4 \%$ and $0.6 \%$ FOS groups is respectively increased by $2.08 \%$ and $2.05 \%(\mathrm{P}<0.05)$. However, there is no significant difference compared with the $0.2 \%$ FOS group and the 
bacitracin zinc group $(\mathrm{P}>0.05)$. The hatching rate of $0.4 \%$ FOS group, $0.6 \%$ FOS group and bacitracin group is respectively increased by $2.05 \%, 2.30 \%$ and $1.34 \%(\mathrm{P}<0.05)$. There was no significant difference in the $0.2 \%$ FOS group, compared with the control group $(\mathrm{P}>0.05)$. In addition, the experiment also observes that the addition of FOS and bacitracin zinc to the diet reduces the number of dead pheasants in yellow broiler hens.

\subsection{Serum Biochemical Indicators}

As can be seen from Table 2, with the increase of the level of FOS, the serum total protein content gradually increases, and the $0.2 \%, 0.4 \%$, and $0.6 \%$ FOS groups are significantly different from the control group $(\mathrm{P}<0.05)$. Compared with the control group, the FOS group can significantly increase serum globulin content $(\mathrm{P}<0.05)$. There is no significant difference in serum albumin content between the groups $(\mathrm{P}>0.05)$. Compared with the control group and the bacitracin zinc group, the serum total cholesterol content of the $0.2 \%$ and $0.4 \%$ FOS groups is significantly decreased $(\mathrm{P}<0.05)$, while the $0.6 \%$ FOS group is not significantly decreased $(\mathrm{P}>0.05)$. Compared with the control group, the addition of FOS and bacitracin zinc can significantly reduce serum triglyceride content $(\mathrm{P}<0.05)$, and also reduced urea nitrogen content to a certain extent $(\mathrm{P}>0.05)$. Compared with the control group and the bacitracin group, the activity of alkaline phosphatase in the serum of the FOS group is significantly increased $(\mathrm{P}<0.05)$, and the activity of aspartate aminotransferase in serum decreases $(\mathrm{P}>0.05)$. There is no significant difference in serum alanine aminotransferase activity $(\mathrm{P}>0.05)$. Compared with the control group, the glucose content in the blood of fructose and bacitracin is increased, but the difference between the groups is not significant $(\mathrm{P}>0.05)$.

Table 2 Effect of Adding FOS and Bacitracin Zinc on Serum Biochemical Indicators of Yellow Broiler Hens

\begin{tabular}{|c|c|c|c|c|c|}
\hline Group & Basic diet & $\begin{array}{c}0.2 \% \text { FOS } \\
\text { group }\end{array}$ & $\begin{array}{c}0.4 \% \text { FOS } \\
\text { group }\end{array}$ & $\begin{array}{c}0.6 \% \text { FOS } \\
\text { group }\end{array}$ & $\begin{array}{c}0.05 \% \\
\text { antibiotics }\end{array}$ \\
\hline total protein $/ \mathrm{g} \cdot \mathrm{L}^{-1}$ & $56.4 \pm 0.38^{\mathrm{c}}$ & $59.91 \pm 1.97^{\mathrm{b}}$ & $60.9 \pm 1.35^{\mathrm{b}}$ & $62.1 \pm 2.10^{\mathrm{a}}$ & $59.7 \pm 1.32^{\mathrm{b}}$ \\
\hline albumin $/ \mathrm{g} \cdot \mathrm{L}^{-1}$ & $26.0 \pm 0.52$ & $25.7 \pm 1.03$ & $22.9 \pm 2.81$ & $27.9 \pm 1.95$ & $23.7 \pm 3.21$ \\
\hline Globulin $/ \mathrm{g} \cdot \mathrm{L}^{-1}$ & $30.4 \pm 4.21^{\mathrm{c}}$ & $43.1 \pm 0.67^{\mathrm{a}}$ & $36.8 \pm 0.37^{\mathrm{b}}$ & $39.0 \pm 2.22^{\mathrm{b}}$ & $36.0 \pm 2.03^{\mathrm{b}}$ \\
\hline Alanine aminot ransferase $/ \mathrm{U} \cdot \mathrm{L}^{-1}$ & $6 \pm 1.27$ & $10 \pm 1.11$ & $7+0.34$ & $9 \pm 0.15$ & $8 \pm 0.58$ \\
\hline Aspartate aminot -ransferase $/ \mathrm{U} \cdot \mathrm{L}^{-1}$ & $225 \pm 36.40$ & $159 \pm 59.9$. & $202 \pm 52.70$ & $216 \pm 48.30$ & $267 \pm 25.40$ \\
\hline alkaline phosphatase $/ \mathrm{U}^{-} \cdot \mathrm{L}^{-1}$ & $466 \pm 19.59^{\mathrm{b}}$ & $508 \pm 20.64^{\mathrm{a}}$ & $595 \pm 16.36^{\mathrm{a}}$ & $530 \pm 25.85^{\mathrm{a}}$ & $462 \pm 30.25^{\mathrm{b}}$ \\
\hline total cholesterol $/ \mathrm{mmol} \cdot \mathrm{L}^{-1}$ & $5.96 \pm 0.08^{\mathrm{a}}$ & $4.21 \pm 0.06^{\mathrm{b}}$ & $3.59 \pm 0.14^{\mathrm{b}}$ & $4.79 \pm 0.75^{\mathrm{a}}$ & $4.82 \pm 0.28^{\mathrm{a}}$ \\
\hline triglyceride $/ \mathrm{mmol} \cdot \mathrm{L}^{-1}$ & $1.37 \pm 0.02^{\mathrm{a}}$ & $0.59 \pm 0.35^{\mathrm{b}}$ & $0.69 \pm 0.20^{\mathrm{b}}$ & $0.98 \pm 0.18^{\mathrm{b}}$ & $1.05 \pm 0.30^{\mathrm{b}}$ \\
\hline Urea nitrogen $/ \mathrm{mmol} \cdot \mathrm{L}^{-1}$ & $1.32 \pm 0.12$ & $1.29 \pm 2.56$ & $0.85 \pm 0.79$ & $0.99 \pm 1.33$ & $1.23 \pm 0.09$ \\
\hline Glucose $/ \mathrm{mmol} \cdot \mathrm{L}^{-1}$ & $11.28 \pm 1.01$ & $12.42 \pm 0.67$ & $13.9 \pm 0.28$ & $12.88 \pm 0.53$ & $12.50 \pm 0.10$ \\
\hline
\end{tabular}

\subsection{Dietary Nutrient Apparent Metabolic Rate}

As can be seen from Table 3, the apparent metabolic rate of crude protein in the diet is the highest in the $0.6 \%$ FOS group $(67.32 \%)$, and is significantly different from the control group and the bacitracin group $(\mathrm{P}<0.05)$. Compared with the control group, the $0.2 \%$ and $0.4 \%$ FOS group respectively increases by $6.80 \%$ and $8.24 \%$ $(\mathrm{P}<0.05)$, but the difference is not significant compared with the bacitracin zinc group $(\mathrm{P}>0.05)$. The apparent metabolic rate of crude fat in the diet of $0.2 \%, 0.4 \%$ and $0.6 \%$ FOS group respectively increases by $6.16 \%, 4.59 \%$ and $3.54 \%(\mathrm{P}<0.05)$, and that of $0.2 \%, 0.4 \%$ FOS group is significantly higher than the bacitracin zinc group $(\mathrm{P}<0.05)$. The apparent metabolic rate of dietary crude fiber of $0.2 \%$ and $0.4 \%$ FOS group is not significantly different from the control group ( $\mathrm{P}>0.05)$, but $0.6 \%$ FOS group is significantly higher than the control group $(\mathrm{P}<0.05)$. There is no significant difference between the $0.6 \%$ FOS group and the bacitracin zinc group $(\mathrm{P}>0.05)$. The addition of FOS and bacitracin zinc can increase the apparent metabolic rate of dietary calcium in yellow broiler hens, but the difference between the groups is not significant $(\mathrm{P}>0.05)$. Compared with the control group, the addition of FOS and bacitracin zinc significantly increases the apparent metabolic rate of total phosphorus in the yellow broiler hens. $0.2 \%, 0.4 \%$ and $0.6 \%$ FOS group and bacitracin zinc group respectively increase by $14.38 \%, \quad 13.98 \%, \quad 17.13 \%$ and $14.76 \% \quad(\mathrm{P}<0.05)$. However, there is no significant difference between the groups with fructose added and the zinc group of bacitracin $(\mathrm{P}>0.05)$. 
Table 3 Effect of FOS and Bacitracin Zinc on Apparent Metabolism Rate of Nutrients in Yellow Broiler Hens

\begin{tabular}{|l|l|l|l|l|l|}
\hline \multicolumn{1}{|c|}{ Group } & \multicolumn{1}{|c|}{ Basic diet } & $\begin{array}{c}0.2 \% \text { FOS } \\
\text { group }\end{array}$ & $\begin{array}{c}0.4 \% \text { FOS } \\
\text { group }\end{array}$ & $\begin{array}{c}0.6 \% \text { FOS } \\
\text { group }\end{array}$ & \multicolumn{1}{c|}{$\begin{array}{c}0.05 \% \\
\text { antibiotics }\end{array}$} \\
\hline crude protein $/ \%$ & $60.29 \pm 1.82 \mathrm{c}$ & $64.39 \pm 1.49 \mathrm{ab}$ & $65.26 \pm 0.55 \mathrm{ab}$ & $67.32 \pm 0.87 \mathrm{a}$ & $63.25 \pm 1.27 \mathrm{~b}$ \\
\hline crude fat $/ \%$ & $81.47 \pm 0.49 \mathrm{c}$ & $86.49 \pm 1.33 \mathrm{a}$ & $85.21 \pm 0.89 \mathrm{a}$ & $84.35 \pm 1.07 \mathrm{ab}$ & $83.46 \pm 1.05 \mathrm{bc}$ \\
\hline Crude fibers $/ \%$ & $13.34 \pm 1.05 \mathrm{~b}$ & $15.12 \pm 0.85 \mathrm{~b}$ & $18.55 \pm 0.77 \mathrm{ab}$ & $20.67 \pm 0.63 \mathrm{a}$ & $18.31 \pm 0.20 \mathrm{ab}$ \\
\hline $\mathrm{Ca} / \%$ & $63.36 \pm 2.35$ & $65.05 \pm 2.79$ & $65.34 \pm 3.05$ & $66.03 \pm 3.21$ & $64.75 \pm 1.52$ \\
\hline total $\mathrm{P} / \%$ & $50.21 \pm 0.52 \mathrm{~b}$ & $57.43 \pm 0.17 \mathrm{a}$ & $57.23 \pm 0.40 \mathrm{a}$ & $58.81 \pm 0.28 \mathrm{a}$ & $57.62 \pm 0.23 \mathrm{a}$ \\
\hline
\end{tabular}

\section{Discussion}

\subsection{Effect of Adding FOS on Laying Performance and Nutrient Metabolism Rate of Chicken}

In this experiment, $0.2 \%, 0.4 \%$ and $0.6 \%$ FOS are added to the diet of high-quality yellow broiler hens to improve egg laying performance and reproductive performance including laying performance rate, egg pass rate, average egg weight, feed-egg ratio, egg fertilization rate and hatching rate. They improve the apparent metabolic rate of nutrients such as crude protein, crude fat, crude fiber and total phosphorus, which are basically consistent with the reports in the reference ${ }^{[1]}$ and reference ${ }^{[2]}$. The mechanism may be that the FOS adjusts the intestinal micro-ecology on the one hand, maintains the intestinal health, which is beneficial to nutrient digestion and absorption. On the other hand, $\mathrm{Xu}$ et al found that the addition of $0.4 \%$ FOS to chicken diets can increase the microvilli height of the ileum and jejunum of the chicken and the ratio of the height of the villus to the depth of the crypt to increase the absorption area ${ }^{[3]}$, thereby increasing the nutrient digestibility. In addition, it may be that FOS promotes L-lactic acid and volatile fatty acids produced by the proliferation of beneficial bacteria, lowering the $\mathrm{pH}$ of the intestinal tract, increasing the solubility of mineral elements, thereby increasing the absorption rate [4].

\subsection{Effect of FOS on Serum Biochemical Indicators of Yellow Broiler Hens}

The amount of globulin in serum is related to the immune function of the body. The addition of FOS in the diet can significantly increase the amount of globulin in the serum and enhance the humoral immunity. In this experiment, FOS are added to the diet of the yellow broiler hens to reduce the content of total cholesterol and triglyceride in serum. Serum triglyceride is one of the main components of blood lipids. FOS have the characteristics of water-soluble dietary fiber, which can absorb lipids in the body and improve lipid metabolism to reduce blood lipid levels. In the experiment, the serum urea nitrogen in the FOS group is decreased.

\subsection{Appropriate Addition Level of FOS in the Diet of Yellow Broiler Hens}

The effect of functional oligosaccharide (prebiotics) is closely related to the structure and amount of dietary supplements. If the added amount is not enough, the beneficial bacteria are difficult to form. If the added amount is too much, it causes waste and increases intestinal osmotic pressure, affecting the balance of intestinal micro-ecology. It is reported that the addition of $1 \%$ FOS to chicken diets results in increased diarrhea in the flock, which reduces production performance. In this experiment, the addition of $0.2 \%-0.6 \%$ FOS in the diet can improve the performance of yellow broiler hens in different degrees. However, from the aspects of laying performance rate, feed-to-egg ratio, fertilization rate and hatching rate of qualified eggs, as well as the serum biochemical indicators of the chicken and the apparent metabolic rate of nutrients, the level of FOS in the corn-soybean meal of high-quality yellow broiler hens is preferably $0.4 \%$.

\subsection{Feasibility of Replacing Bacitracin Zinc with FOS in the Production of Yellow Broiler Hens}

The results of this experiment show that with $0.2 \%-0.6 \%$ of FOS added to the diet, and the laying performance, feed-egg ratio and hatching egg rate of yellow broiler hens are not significantly different or different from those of the added bacitracin zinc. Serum total cholesterol, triglyceride and other lipid content and serum urea nitrogen content are lower than the bacitracin zinc group. Serum total protein and globulin levels are higher than those of bacitracin zinc group. The apparent metabolic rate of nutrients such as crude protein, crude fat, calcium and total phosphorus in the diet is was also higher than that of the bacitracin zinc group. Therefore, the comprehensive analysis suggests that FOS can not only replace bacitracin zinc in the diet of yellow broiler hens, but also improve the laying performance, physiological and biochemical functions of yellow-feathered broiler breeders, enhancing animal immune system and health to improve feed utilization.

\section{Conclusion}

Based on the results of the experiment, it is believed that FOS instead of dietary antibiotics (bacitracin zinc) is fed to yellow broiler hens, which can improve the performance of yellow broiler hens, the metabolizability and feed utilization. It can reduce serum lipid content and enhance animal immune function and body health. Compared with bacitracin zinc, functional FOS, as a new type of green feed additive with no residue and no 
bacterial resistance, have unique advantages and are worthy of development and utilization in the production of yellow broiler hens. The addition level of FOS in corn-soybean meal diets is preferably $0.4 \%$.

\section{References}

1. Delzenne N, Aertssens J, Verplaetse H, et al.Effect of fermentable fructo-oligosaccharides on mineral, nitiogen and energy difetive balance in the $\operatorname{rat}[J]$.Life Sciences, 1955,57(17):1579-1587.

2. Ohta A M, Ohstuki S, Baba S, et al. Calcium and magnesium absorption from the colon and rectum are increased in rats fed fructooligosaccharides[J]. J Nutr,1995,125:2417-2425.

3. $\mathrm{Xu} \mathrm{Z} \mathrm{R,Hu} \mathrm{C} \mathrm{H} \mathrm{,Xia} \mathrm{M} \mathrm{S,et} \mathrm{al.Effects} \mathrm{of} \mathrm{dietary}$ fructo-oligosaccharide on digestive enzyme activities, intestinal microflora and morphology of male broilers[J].Poultru Sci,2003,82:1030-1036.

4. Zhu Z H, Li Y M, Wang Z Y. Research on the Role of Fructooligosaccharides in the Absorption of caloium [J]. China Dairy Industry, 2008,8(36):63-64. 